\title{
Internet Addiction: \\ A Closer Look at Multidimensional Parenting Practices and Child Mental Health
}

\author{
Yi-Ping Hsieh, $\mathrm{PhD},{ }^{1}$ April Chiung-Tao Shen, $\mathrm{PhD},{ }^{2} \mathrm{Hsi}$-Sheng Wei, $\mathrm{PhD}{ }^{3}$ \\ Jui-Ying Feng, DNS, ${ }^{4}$ Soar Ching-Yu Huang, $\mathrm{PhD}^{5}$ and Hsiao-Lin Hwa, $\mathrm{PhD}^{6}$
}

\begin{abstract}
This study aimed to examine how both psychosocial variables (authoritative, authoritarian, and shaming, and parent-child relationships) and psychological symptoms were associated with Internet addiction, while controlling for the sociodemographic variable (child gender). A national proportionately stratified random sample of 6,233 fourth-grade primary school students in Taiwan participated in the study. Hierarchical regression models were performed to test the research hypotheses. The results show that psychological symptoms, authoritarian parenting, and shaming were positively associated with Internet addiction, whereas authoritative parenting and positive parent-child relationship were negatively associated with Internet addiction. Girls had lower levels of Internet addiction than boys. In conclusion, this study demonstrates the direct effects of child mental health status, multidimensional parenting practices, and family relationship on Internet addiction in children, and the importance of early individual- and family-based prevention and intervention in addressing related public health concerns of Internet addiction in children. The cultural perspectives of parenting and implications of these findings are discussed.
\end{abstract}

Keywords: Internet addiction, parenting, psychological symptoms, parent-child relationship, shaming

\section{Introduction}

\section{Internet addiction and the multidimensional risk factors}

I NTERNET HaS BECOME an important part of our life. People rely on the Internet to do lots of things to make life more convenient, efficient, and interesting. However, we need to be aware of the dark side of Internet use-Internet addiction. Internet addiction refers to excessive time spent on Internet activities, resulting in behavioral impairment and psychological dysfunction in daily life. ${ }^{1-3}$ Considering the levels of self-control and brain development, children and adolescents are more vulnerable to Internet addiction than adults when highly exposed to the Internet. Internet addiction itself is considered as only the tip of the iceberg. To prevent or intervene in problems of Internet addiction, we need to first understand the risk factors from a multidimensional per- spective. Four major factors associated with Internet addiction were identified: Sociodemographic variables, Internet use variables, psychosocial factors, and psychological symptoms. ${ }^{4}$ First, sociodemographic variables, such as male gender, higher family income levels, and living in rural areas were associated with Internet addiction. ${ }^{5-7}$ Second, Internet use variables, such as increased online time, early Internet exposure, and the use of Internet applications were linked to Internet addiction. ${ }^{8-10}$ Third, psychological factors, such as loneliness, impulsiveness, and negative emotion avoidance; and social factors, such as child maltreatment experiences, peer victimization, low social support, and lack of family love were associated with Internet addiction. ${ }^{11-16}$ Finally, psychological symptoms, such as depression, anxiety, attention-deficit/hyperactivity disorder, and general psychological problems were linked to Internet addiction. ${ }^{10,15-17}$

${ }^{1}$ Department of Social Work, University of North Dakota, Grand Forks, North Dakota.

${ }^{2}$ Department of Social Work, National Taiwan University, Taipei, Taiwan.

${ }^{3}$ Department of Social Work, National Taipei University, New Taipei City, Taiwan.

${ }_{5}^{4}$ Department of Nursing, National Cheng Kung University and Hospital, Tainan, Taiwan.

${ }^{5}$ Psychology Department, Bournemouth University, Fern Barrow, United Kingdom.

${ }^{6}$ Department and Graduate Institute of Forensic Medicine, National Taiwan University, Taipei, Taiwan. 


\section{The current study}

This study aimed to expand previous research to examine how both psychosocial variables (authoritative, authoritarian, and shaming, and parent-child relationships) and psychological symptoms were associated with Internet addiction, while controlling for the sociodemographic variable (child gender). Previous research has documented that authoritative parenting and a secure family environment were related to positive child outcomes. ${ }^{18,19}$ In contrast, authoritarian parenting, which is over-intrusive and punitive was associated with child maladjustment, such as Internet addiction. $^{20}$ In Chinese/Taiwanese culture, several parenting practices and social attitudes were emphasized: encouragement of modesty, protection, directiveness, shaming/love withdrawal, and maternal involvement. ${ }^{21}$ Compared to Western societies, shaming is more commonly used by Chinese parents as a psychological manipulation tool to effectively control children and gain their immediate compliance. $^{22}$ Shaming refers to a parenting practice that invoke children's feeling of shame to teach their children what is expected and socially acceptable behaviors/performance. ${ }^{23}$ When children fail to meet these expectations, Chinese parents pressure their children to internalize the feeling of shame and guilt. ${ }^{24}$ Shaming was positively related to withdrawn behaviors among Chinese preschoolers. ${ }^{25}$ However, another study found that shaming was not related to problem behaviors in Chinese school-age children. ${ }^{26} \mathrm{We}$ would like to examine how shaming, along with authoritative and authoritarian parenting are related to Internet addiction among Chinese/Taiwanese school-age children.

\section{Rationale and hypotheses}

Based on the self-medication hypothesis and escape mechanism, Hsieh et al. ${ }^{12,13}$ suggested that high usage of the Internet may be a maladaptive/dysfunctional form of a coping strategy for children with trauma and victimization experiences to reduce their psychological symptoms and escape from real life problems by entering the cyber world for comfort and shelter, and consequently increase their risks of Internet addiction. In addition, when children lacked support, resources, and positive relationships in the real world, they were more likely to turn to the cyber world to compensate for their needs of love, happiness, and sense of belonging. Thus, we hypothesized that authoritarian parenting, shaming, and psychological symptoms would increase the likelihood of Internet addiction, whereas authoritative parenting and positive parent-child relationship would reduce the risk of Internet addiction.

\section{Methods}

\section{Participants}

This study is part of the Longitudinal Study of Children's and Adolescents' Family and Social Experiences (LSCAFSE). The Institutional Review Board of the National Taiwan University Hospital declared that the LSCAFSE was consistent with the protection of the rights and welfare of human subjects. We stratified the sample by geographical location across Taiwan (19 counties or cities in total) and randomly selected districts to increase representation. A total of 314 public elementary schools agreed to participate in the study.
The final sample of this study consisted of 6,233 fourth-grade students (50.3 percent boys) who had parental consent and whose data were valid.

\section{Procedure}

Informed consent was obtained from all individual participants included in the study. Self-report questionnaires were distributed to consenting students in group sessions at schools. Before administering the questionnaires, trained research assistants explained the research purpose and procedures to the students and emphasized the voluntary and confidential nature of the research. The students were informed of their right to withdraw from participation at any time. Finally, the research assistants gave a stationery set to each student who completed the survey to express appreciation for their time and effort.

\section{Measures}

The questionnaire was examined for content validity by a group of seven experts (four child development scholars, one sociologist, one clinical social worker, and one statistician), and it was administered to 726 pilot-study participants. The LSCAFSE research team modified some measures according to the results of the pilot study's internal consistency analysis and principal component analysis, along with suggestions from scholars and other experts. Psychometrics of these measures was examined again after formal data were collected.

Internet addiction. We adapted items from the Chen Internet Addiction Scale (CIAS) to measure Internet addiction. ${ }^{27}$ The original scale contains 26 items covering two domains: core symptoms (14 items) and related problems (12 items). Considering the attention span of children and the length of the questionnaire, in this study we used a short version of the scale by selecting items that have high factor loadings (higher than 0.55 or 0.60 ). This subscale used in this study contains 10 items, including core symptoms (6 items) and related problems ( 4 items). The core symptoms comprise compulsion symptoms, withdrawal symptoms, and tolerance, and the related problems comprise interpersonal/health problems and time-management problems. Items are rated on a 5-point scale anchored by 1 (very false) to 5 (very true). The reliability of the scale was calculated using a Cronbach's alpha of 0.88 , demonstrating strong internal consistency. Construct validity was examined via factor analysis that confirmed the proposed two-factor structure and explained 60 percent of the variance.

Psychological symptoms. The Brief Symptom Rating Scale (BSRS-5) is composed of five self-report items for participants to report their psychological symptoms in the past week. $^{28}$ It is derived from the 50-item BSRS that measures anxiety (feeling tense or high-strung), hostility (feeling easily annoyed or irritated), depression (feeling depressed or in a low mood), interpersonal sensitivity (feeling inferior to others), and additional symptoms (i.e., having trouble falling asleep in the past week). The score for each item ranges from 0 to $4(0=$ not at all; $1=$ a little bit; $2=$ moderately; $3=$ quite a bit; and $4=$ extremely). The scores were internally consistent $(\alpha=0.84)$.

Parenting. Authoritative, authoritarian, and shaming were measured. We adapted the questionnaire items from the 
Parenting Styles and Dimensions Questionnaire (PSDQ), which assesses children's perceptions of their parent's parenting styles. ${ }^{21,29}$ Considering the attention span of children and the length of the questionnaire, we used a short version of the questionnaire by selecting items that have high factor loadings in each subscale. Children answered four items on authoritative parenting (Cronbach's $\alpha=0.84$ ), three items on authoritarian parenting $(\alpha=0.72)$, and two items on shaming $(\alpha=0.64)$. Shaming is the most common practice in Chinese parenting. Sample items are: "My parents tell me that they get embarrassed when I don't meet expectations"; "My parents make me feel guilty when I don't meet their expectations." All items were rated on a 5-point scale anchored by 1 (never) and 5 (always). Mean scores of each dimension were used for subsequent statistical analyses.

Parent-child relationship. The scale consists of four items (two items regarding the father and the same two items regarding the mother) on a 5-point rating scale (from $1=$ "never" to $5=$ "always") for children to answer. Two questions were as follows: "I have a good relationship with my father" (mother); "My father (mother) is my role model." The mean score was calculated. The scores were internally consistent $(\alpha=0.75)$.

\section{Statistics}

Statistical analysis was performed with the SPSS Statistical Package for Windows, version 24. First, descriptive statistics were used to assess the distribution of Internet addiction, psychological symptoms, child-perceived parenting practices, and the parent-child relationship. Second, we conducted correlational analyses using the Pearson coefficient of correlation to illustrate interrelationships between each of the variables. Finally, we conducted hierarchical regression to examine the effects of multidimensional parenting practices, parent-child relationship, and psychological symptoms on Internet addiction, after controlling for gender.

\section{Results}

\section{Descriptive statistics and correlations}

Table 1 presents the correlation coefficients among all study variables and the descriptive statistics of the means and standard deviations of the variables.

\section{Effects of psychological symptoms and parenting on child Internet addiction}

Hierarchical regression analyses were used to examine whether children's psychological symptoms, child-perceived authoritative, authoritarian, and shaming in addition to parent-child relationship were significant contributors to Internet addiction in children, after controlling for gender. Table 2 summarizes the results from the hierarchical regression. The sociodemographic variable (child gender) was entered into the regression model of Internet addiction in the first step (Model 1). Psychological symptom was entered into the regression model in the second step (Model 2). Finally, psychosocial variables (authoritative, authoritarian, shaming, and parent-child relationship) were entered in the third step (Model 3).

The results showed that child gender explained 3 percent of the variance $\left(R^{2}=0.03, p<0.001\right)$. Adding psychological symptoms significantly increased 8 percent of variance explained $\left(\Delta R^{2}=0.08, p<0.001\right)$. Moreover, adding parenting practices and parent-child relationship significantly increased 4 percent of variance explained $\left(\Delta R^{2}=0.04\right.$, $p<0.001)$. In total, these sociodemographic, psychological symptoms, and psychosocial variables explained 14 percent of the variance $\left(R^{2}=0.14, p<0.001\right)$, and the model was significant. The regression coefficients indicated that psychological symptoms $(\beta=0.21)$, authoritarian parenting ( $\beta=0.06)$, and shaming $(\beta=0.08)$ were positively associated with Internet addiction $(p<0.001)$, whereas authoritative parenting $(\beta=-0.10)$ and parent-child relationship $(\beta=-0.08)$ were negatively associated with Internet addiction $(p<0.001)$. Boys had higher levels of Internet addiction than girls $(\beta=-0.15, p<0.001)$. To further examine the potential moderating effect of gender on the relationships between the psychosocial correlates and internet addiction, we conducted additional regression analyses. We found moderating effect of gender between authoritarian parenting and Internet addiction $(\beta=-0.04, p<0.05)$, and between psychological symptoms and Internet addiction $(\beta=-0.06$, $p<0.001$ ). The results revealed that gender (boys) amplified the effects of psychological symptoms and authoritarian parenting on Internet addiction.

\section{Discussion}

This study extends previous research that concerns the impact of child mental health, parenting practices, and

Table 1. Bivariate Correlations, Means, and Standard Deviations for Variables in the Models

\begin{tabular}{|c|c|c|c|c|c|c|c|}
\hline & 1 & 2 & 3 & 4 & 5 & 6 & 7 \\
\hline 1. Child gender & - & & & & & & \\
\hline 2. Psychological symptoms & 0.02 & - & & & & & \\
\hline 3. Authoritative parenting & $0.05 * *$ & $-0.20 * *$ & - & & & & \\
\hline 4. Authoritarian parenting & $-0.14 *$ & $0.25^{* *}$ & $-0.20 * *$ & - & & & \\
\hline 5. Chinese-specific parenting & $-0.08 * *$ & $0.24 * *$ & $-0.06^{* *}$ & $0.49 * *$ & - & & \\
\hline 6. Parent-child relationships & $0.05 * *$ & $-0.18 * *$ & $0.61 * *$ & $-0.16^{* *}$ & $-0.04 * *$ & - & \\
\hline 7. Internet addiction & $-0.16^{* *}$ & $0.27 * *$ & $-0.21 * *$ & $0.20 * *$ & $0.17 * *$ & $-0.19 * *$ & - \\
\hline Mean & - & 3.57 & 3.88 & 2.29 & 2.24 & 4.02 & 1.82 \\
\hline$S D$ & - & 3.72 & 0.96 & 0.96 & 1.12 & 0.85 & 0.77 \\
\hline
\end{tabular}

Note: $S D$ is standard deviation. Codes for gender are $1=$ male, $2=$ female.

$* p<0.05$.

$* * p<0.01$ 
Table 2. Summary of Hierarchical Regression Analysis for Variables Predicting INTERNET AdDiction $(N=6,233)$

\begin{tabular}{|c|c|c|c|c|c|c|}
\hline \multirow[b]{2}{*}{ Variables } & \multicolumn{3}{|c|}{ Model 1} & \multicolumn{3}{|c|}{ Model 2} \\
\hline & $B$ & $S E B$ & $\beta$ & $B$ & $S E B$ & $\beta$ \\
\hline Child gender & -0.26 & 0.02 & $-0.17 * * *$ & -0.22 & 0.02 & $-0.15^{* * *}$ \\
\hline Psychological symptoms & 0.06 & 0.00 & $0.27 * * *$ & 0.04 & 0.00 & $0.21 * * *$ \\
\hline Authoritative parenting & & & & -0.08 & 0.01 & $-0.10 * * *$ \\
\hline Authoritarian parenting & & & & 0.05 & 0.01 & 0.06 *** \\
\hline Chinese-specific parenting & & & & 0.05 & 0.01 & $0.08 * * *$ \\
\hline Parent-child relationship & & & & -0.07 & 0.01 & $-0.08 * * *$ \\
\hline
\end{tabular}

Note: Codes for gender are $1=$ male, $2=$ female .

$* * * p<0.001$.

parent-child relationship on Internet addiction. This study addressed the increasing problems of Internet addiction among Taiwanese children, and furthered our knowledge of authoritative, authoritarian, and shaming and parent-child relationships in Taiwanese families, and how these family factors and mental health symptoms were related to Internet addiction.

\section{Parenting and Internet addiction}

The key findings were consistent with the hypotheses that children who reported psychological symptoms and perceived authoritarian and shaming were more likely to have Internet addiction. In contrast, children who perceived authoritative parenting and positive parent-child relationship were less likely to have Internet addiction. Similar to the results from Western society about the negative impact of shaming on children's self-esteem and internalizing problems, shaming also had negative impact on the use of the Internet. ${ }^{30}$ Although shaming is commonly used by Chinese parents to "help" their children meet expectations, behave, and perform well, shaming can also over-pressure children and push them away. In contrast to the independent culture that focuses on personal choice and need along with autonomy and separateness, Chinese parents influenced by the interdependent culture give priority to group/family goals; focus on norms, duties, and relatedness; and maintain interpersonal relationships based on roles and obligations. ${ }^{31,32}$ Chinese parents take full responsibility for their children's success or failure, and the glory or shame that followed is not the child's personal business, but the whole family's reputation. Therefore, Chinese parents tend to be dominative and controlling in the parent-child relationships, make plans and decisions for their children, make children feel and behave the way parents expect, and pressure children not to bring shame to the family. Internet addiction was suggested to be a self-medicating behavior and a maladaptive form of an avoidance coping strategy. ${ }^{12,13}$ When children perceived a lot of shaming from parents and internalized their feelings of shame, they may try hard to avoid or reduce this feeling and thus escape into the cyber world to feel pleasure, regain positive self-image, and reduce responsibility of not meeting expectations or "failures" in real life.

Speaking of cultural perspective, the Confucianism emphasizes on filial piety, a guiding principle governing Chi- nese patterns of socialization. ${ }^{33,34}$ Filial piety teaches Chinese families how children should behave toward their parents and also justifies absolute parental authority over children, and it shares some similar ideas with authoritarianism. ${ }^{35}$ Authoritarian filial piety forces children to suppress their own wishes and comply with their parents' expectations. Parents who hold authoritarian filial piety attitude usually exert coercive and instructive control on children's behaviors. Although parental controlling was viewed as an expression of "caring" for Chinese parents, children may not feel the same way while they are being harshly controlled. Children who perceived higher levels of authoritarian parenting may view parental controlling as a barrier and obstacle of healthy parent-child communication. Consequently, children tended to shut the door of communication with parents and engage more in online activities to seek for comfort and avoid conflicts with parents. The more time they spend on Internet to avoid stressful family interaction, the higher chance they get to exhibit Internet addiction symptoms.

On the other hand, authoritative parenting and positive parent-child relationship are related to lower levels of Internet addiction. Previous research has found that youth with Internet addiction reported higher levels of parent-child conflict, dissatisfaction with their families, and having less warm and supportive parents, compared to non-Internet addiction youth. ${ }^{36}$ In contrast, when parents are more warm, supportive, and open-minded for two-way discussion and communication, they are more likely to establish positive relationships with their children, and this relationship can serve as a foundation for children's positive development and reduce the risk of Internet addiction.

\section{Mental health and Internet addiction}

Besides negative parenting, such as over-intrusive, punitive, authoritarian, and shaming parenting, child mental health also plays an important role in predicting Internet addiction. Psychological symptoms, such as depression, anxiety, sleep disturbance, and self-contempt were related to Internet addiction among college students and adolescents. $^{37,38}$ Our results indicated similar relationships between psychological symptoms and Internet addiction among children (the fourth graders). The self-medication hypothesis of addictive disorders suggested that one will 
utilize alcohol or drugs to reduce negative emotions instead of using a healthier strategy. ${ }^{39}$ Similarly, the underlying premise of the self-medication hypothesis of Internet addiction is that children with high negative emotions or psychological symptoms have higher risks of developing a pattern of problematic use of the Internet over time to ease their psychological distress, leading to adverse consequences such as Internet addiction.

\section{Strengths and limitations}

This study is one of the first comprehensive national epidemiologic studies of Taiwanese children to provide unique insights into the complex relationships among multidimensional parenting practices, family interaction, child mental health, and child Internet addiction. Moreover, our use of a large sample size with a stratified random sampling design has honed our representation and generalization. However, several limitations need to be acknowledged. The crosssectional design may have impeded the inferences we have drawn about links among the study variables and it has been difficult to determine the direction of the influence. Moreover, the data were collected from a single source, namely self-report by children for both predictors and the outcome, which raises concerns of shared method variance. Thus, future research should collect data from both children and parents to reduce measurement bias and increase the validity of the findings. In addition, the data should be collected longitudinally to investigate the trajectories of parenting practices, parent-child relationship, psychological symptoms, and Internet addiction as children grow older and transit into adolescence.

\section{Implications}

The study provides valuable information for clinicians working to support students with problematic Internet use. One important consideration when working with children with Internet addiction is to realize that Internet addiction is only the tip of the iceberg. Prevention and intervention should not only focus on the behavior itself. Clinicians should identify the underlying problems faced by children, including both individual and family levels, such as their mental health status, perceived parenting, and parent-child relationships. The results provided clinicians with evidence for how an individual's mental health and family interactions were associated with Internet addiction among school-age children. Finally, those who work with families, such as pediatricians, may provide connections to effective parenting support programs for these families.

\section{Conclusions}

Our study expanded on previous research by demonstrating how both psychological symptoms and psychosocial variables (authoritative, authoritarian, and shaming, and parent-child relationships) were associated with Internet addiction, while controlling for the sociodemographic variable (child gender). School-age children who reported themselves with psychological symptoms and perceived authoritarian and shaming were more likely to have Internet addiction. In contrast, children who perceived authoritative parenting and positive parent-child relationships were less likely to have Internet addiction. Internet addiction itself is like the tip of the iceberg. When looking for effective prevention and intervention/solutions of Internet addiction, we need to investigate the multidimensional risk and protective factors first. By examining the personal and psychosocial levels, the findings indicated that psychological symptoms, authoritarian parenting, and shaming were risk factors of Internet addiction, whereas authoritative parenting and positive parent-child relationships were protective factors of Internet addiction among Taiwanese school-age children. Besides the Internet addiction behavior itself, we should pay attention to their mental health status and family interactions.

\section{Acknowledgments}

This work was supported by the National Taiwan University (NTU) Children and Family Research Center.

\section{Author Disclosure Statement}

No competing financial interests exist.

\section{References}

1. Block JJ. Issues for DSM-V: Internet addiction. American Journal of Psychiatry 2008; 165:306-307.

2. Chou C, Condron L, Belland JC. A review of the research on Internet addiction. Educational Psychology Review 2005; 17:363-388.

3. Young KS. Internet addiction: the emergence of a new clinical disorder. Cyberpsychology \& Behavior 1998; 1: 237-244.

4. Kuss DJ, Griffiths MD, Karila L, et al. Internet addiction: a systematic review of epidemiological research for the last decade. Current Pharmaceutical Design 2014; 25:40264052.

5. Ak S, Koruklu N, Yilmaz Y. A study on Turkish adolescent's Internet use: possible predictors of Internet addiction. CyberPsychology, Behavior and Social Networking 2013; 16:205-209.

6. Lam LT, Peng ZW, Mai JC, et al. Factors associated with Internet addiction among adolescents. Cyberpsychology \& Behavior 2009; 12:551-555.

7. Yen $\mathrm{CF}$, Ko $\mathrm{CH}$, Yen JY, et al. Multi-dimensional discriminative factors for Internet addiction among adolescents regarding gender and age. Psychiatry and Clinical Neurosciences 2009; 63:357-364.

8. Beutel ME, Braehler E, Glaesmer H, et al. Regular and problematic leisure-time Internet use in the community: results from a German population-based survey. Cyberpsychology, Behavior and Social Networking 2011; 14:291296.

9. Kuss DJ, Griffiths MD, Binder JF. Internet addiction in students: prevalence and risk factors. Computers in Human Behavior 2013; 29:959-966.

10. Ni X, Yan H, Chen S, et al. Factors influencing Internet addiction in a sample of freshmen university students in China. Cyberpsychology \& Behavior 2009; 12:327-330.

11. Bozoglan B, Demirer V, Sahin I. Loneliness, self-esteem, and life satisfaction as predictors of Internet addiction: a cross-sectional study among Turkish university students. Scandinavian Journal of Psychology 2013; 54:313-319.

12. Hsieh YP, Shen ACT, Wei HS, et al. Associations between child maltreatment, PTSD, and Internet addiction among 
Taiwanese students. Computers in Human Behavior 2016; 56:209-214.

13. Hsieh YP, Shen ACT, Wei HS, et al. Multidimensional victimizations and Internet addiction among Taiwanese children. Chinese Journal of Psychology 2016; 58:217-231.

14. Huang RL, Lu Z, Liu JJ, et al. Features and predictors of problematic Internet use in Chinese college students. Behavior \& Information Technology 2009; 28:485-490.

15. Lin M-P, Ko H-C, Wu JY-W. Prevalence and psychosocial risk factors associated with Internet addiction in a nationally representative sample of college students in Taiwan. Cyberpsychology, Behavior and Social Networking 2011; 14:741-746.

16. Tsai HF, Cheng SH, Yeh TL, et al. The risk factors of Internet addiction-a survey of university freshmen. Psychiatry Research 2009; 167:294-299.

17. Yen J-Y, Yen C-F, Chen C-S, et al. The association between adult ADHD symptoms and Internet addiction among college students: the gender difference. Cyberpsychology \& Behavior 2009; 12:187-191.

18. Carlo G, Mestre MV, Samper P, et al. The longitudinal relations among dimensions of parenting styles, sympathy, prosocial moral reasoning and prosocial behaviors. International Journal of Behavioral Development 2011; 35:116124.

19. Levin KA, Dallago L, Currie C. The association between adolescent life satisfaction, family structure, family affluence and gender differences in parent-child communication. Social Indicators Research 2012; 106:287-305.

20. Huang X, Zhang H, Li M, et al. Mental health, personality, and parental rearing styles of adolescents with Internet addiction disorder. Cyberpsychology, Behavior, and Social Networking 2010; 13:401-406.

21. Wu P, Robinson CC, Yang C, et al. Similarities and differences in mothers' parenting of preschoolers in China and the United States. International Journal of Behavioral Development 2002; 1:481-491.

22. Helwig CC, To S, Wang Q, et al. Judgments and reasoning about parental discipline involving induction and psychological control in China and Canada. Child Development 2014; 85:1150-1167.

23. Fung H, Chen ECH. Across time and beyond skin: self and transgression in the everyday socialization of shame among Taiwanese preschooler children. Social Development 2001; 10:419-437.

24. Fung H. Becoming a moral child: the socialization of shame among young Chinese children. Ethos 1999; 27: 180-209.

25. Nelson LJ, Hart CH, Wu B, et al. Relations between Chinese mothers' parenting practices and social withdrawal in early childhood. International Journal of Behavioral Development 2006; 30:261-271.

26. Fung J, Lau AS. Tough love or hostile domination? Psychological control and relational induction in cultural context. Journal of Family Psychology 2012; 26:966-975.
27. Chen SH, Weng LJ, Su YJ, et al. Development of a Chinese Internet addiction scale and its psychometric study. Chinese Journal of Psychology 2003; 45:279-294.

28. Lee MB, Lee YJ, Yen LL, et al. Reliability and validity of using the Brief Psychiatric Symptom Rating Scale in clinical practice. Journal of the Formosan Medical Association 1990; 89:1081-1087.

29. Robinson CC, Mandleco B, Olsen SF, et al. (2001). Handbook of family measurement techniques. Vol. 3: instruments and Index. In: Touliatos J, Perlmutter BF, Strauss MA, Holden GW, eds. The Parenting Styles and Dimensions Questionnaire (PSDQ). Thousand Oaks, CA: Sage, pp. 319-321.

30. Barber BK, Harmon EL. (2002). Violating the self: parental psychological control of children and adolescents. In Barber BK, ed. Intrusive parenting: how psychological control affects children and adolescents. Washington, DC: American Psychological Association, pp. 15-52.

31. Hollos M, Leis PE. Remodeling concepts of the self: an Ijo example. Ethos 2001; 29:371-387.

32. Markus HR., Conner A. (2014). Clash!: how to thrive in a multicultural world. New York: Penguin.

33. Ho DYF. (1986). Chinese patterns of socialization: a critical review. In Bond $\mathrm{MH}$, ed. The psychology of the Chinese people. Hong Kong: Oxford University Press, pp. 1-37.

34. Ho DYF. Socialization in contemporary mainland China. Asian Thought and Society 1989; 14:136-149.

35. Yeh KH, Bedford O. A test of the dual filial piety model. Asian Journal of Social Psychology 2003; 6:215-228.

36. Li W, Garland EL, Howard MO. Family factors in Internet addiction among Chinese youth: a review of English-and Chinese-language studies. Computers in Human Behavior 2014; 31:393-411.

37. Yao B, Han W, Zeng L, et al. Freshman year mental health symptoms and level of adaptation as predictors of Internet addiction: a retrospective nested case-control study of male Chinese college students. Psychiatry Research 2013; 210: 541-547.

38. Kawabe K, Horiuchi F, Ochi M, et al. Internet addiction: prevalence and relation with mental status in adolescents. Psychiatry and Clinical Neurosciences 2016; 70:405-412.

39. Shadur JM, Hussong AM, Haroon M. Negative affect variability and adolescent self-medication: the role of the peer context. Drug and Alcohol Review 2015; 34:571-580.

Address correspondence to: Prof. Yi-Ping Hsieh Department of Social Work University of North Dakota 225 Centennial Drive, Stop 7135 Grand Forks, ND 58202

E-mail: yiping66@gmail.com 